$\underline{\text { Review article }}$

\title{
Treatment Recommendations for Chronic Myeloid Leukemia
}

\author{
Michele Baccarani ${ }^{1}$, Fausto Castagnetti ${ }^{2}$, Gabriele Gugliotta ${ }^{2}$, Francesca Palandri ${ }^{2}$ and Gianantonio Rosti ${ }^{2}$ \\ ${ }^{1}$ Department of Hematology and Oncology "L. and A. Seràgnoli", University of Bologna, Bologna, Italy. \\ ${ }^{2}$ Institute of Hematology "L. and A. Seràgnoli", Department of Specialty, Diagnostic and Experimental Medicine, \\ University of Bologna, S.Orsola-Malpighi University Hospital, Bologna, Italy.
}

Correspondence to: Fausto Castagnetti, MD. Institute of Hematology "L. and A. Seràgnoli", S.Orsola-Malpighi University Hospital, Via Massarenti 9, 40138 Bologna, Italy. Tel: +39 3493199142, Fax: +39 051 6364037. Email: fausto.castagnetti@unibo.it

Competing interests: The authors have declared that no competing interests exist.

Published: January 2, 2014

Received: November 11, 2013

Accepted: November 30, 2013

Citation: Mediterr J Hematol Infect Dis 2014, 6(1): e2014005, DOI: 10.4084/MJHID.2014.005

This article is available from: http://www.mjhid.org/article/view/12497

This is an Open Access article distributed under the terms of the Creative Commons Attribution License (http://creativecommons.org/licenses/by/2.0), which permits unrestricted use, distribution, and reproduction in any medium, provided the original work is properly cited.

\begin{abstract}
.
The first treatment of chronic myeloid leukemia (CML) included spleen $x$-radiation and conventional drugs, mainly Busulfan and Hydroxyurea. This therapy improved the quality of life during the chronic phase of the disease, without preventing nor significantly delaying the progression towards advanced phases. The introduction of allogeneic stem cell transplantation (alloSCT) marked the first important breakthrough in the evolution of CML treatment, because about $50 \%$ of the eligible patients were cured. The second breakthrough was the introduction of human recombinant interferon-alfa, able to achieve a complete cytogenetic remission in $15 \%$ to $30 \%$ of patients, with a significant survival advantage over conventional chemotherapy. At the end of the last century, about 15 years ago, all these treatments were quickly replaced by a class of small molecules targeting the tyrosine kinases (TK), which were able to induce a major molecular remission in most of the patients, without remarkable side effects, and a very prolonged life-span. The first approved TK inhibitor (TKI) was Imatinib Mesylate (Glivec or Gleevec, Novartis). Rapidly, other TKIs were developed tested and commercialized, namely Dasatinib (Sprycel, Bristol-Myers Squibb), Nilotinib (Tasigna, Novartis), Bosutinib (Busulif, Pfizer) and Ponatinib (Iclusig, Ariad). Not all these compounds are available worldwide; some of them are approved only for second line treatment, and the high prices are a problem that can limit their use. A frequent update of treatment recommendations is necessary. The current treatment goals include not only the prevention of the transformation to the advanced phases and the prolongation of survival, but also a length of survival and of a quality of life comparable to that of non-leukemic individuals. In some patient the next ambitious step is to move towards a treatment-free remission. The CML therapy, the role of alloSCT and the promising experimental strategies are reviewed in the context of the new therapeutic goals.
\end{abstract}


Introduction. The first effective treatment of chronic myeloid leukemia (CML) included x-radiation to the spleen and conventional chemotherapeutic drugs, mainly Busulfan (BUS) and Hydroxyurea (HU). This therapy helped to limit the expansion of the myeloid tissue, improved significantly the quality of life during the chronic phase (CP) of the disease, but did neither prevent nor delay significantly the progression towards accelerated and blastic phase (AP, BP), with a limited effect on overall survival (OS). ${ }^{1-4}$ The introduction of allogeneic stem cell transplantation (alloSCT) marked the first important breakthrough in the evolution and the outcome of CML, because about $50 \%$ of the patients who were eligible for alloSCT became Philadelphia-negative, BCR-ABL negative, and were cured. Unfortunately, the best success of allo SCT were in patients less than 40 years old, while the median age at diagnosis is close to 60 years, and the cure was frequently linked to development of a chronic graftversus-host-disease (cGVHD). ${ }^{1,25-7}$

The second breakthrough in therapy was the introduction of human recombinant interferon-alfa (rIFN $\alpha)$, that was able to achieve a complete cytogenetic remission in $15 \%$ to $30 \%$ of patients, and provided a significant survival advantage over conventional chemotherapy. ${ }^{1,2,8}$ At the end of the last century, about 15 years ago, all these treatments were quickly displaced by the discovery of a class of small molecules targeting the tyrosine kinases (TK), particularly the BCR-ABL TK, that is the cause of the leukemic transformation and the leukemic characteristics of $\mathrm{Ph}+$ hematopoietic stem cells. ${ }^{2}$ The first approved TK inhibitor (TKI) was Imatinib Mesylate (Glivec or Gleevec, Novartis), that is still the CML standard treatment for many patients. ${ }^{1,6,9,10}$ Rapidly, other TKIs were developed tested and commercialized, namely Dasatinib (Sprycel, BristolMyers Squibb), Nilotinib (Tasigna, Novartis), Bosutinib (Busulif, Pfizer) and Ponatinib (Iclusig, Ariad). ${ }^{11-17}$ Not all these compounds are available worldwide; some of them are approved only for second line treatment, and the high prices are a problem that can limit their use. ${ }^{18}$ However, overall they provide an extraordinary inventory of active agents which we should learn to use to optimize the treatment of CML, with the purpose of avoiding death from leukemia, but also avoiding deaths and complications from treatment, improving the quality of life, achieving a cure, and also making better and proper use of the financial resources, that are never unlimited.

The Goals of Treatment. Until the introduction of the TKIs, the goals of CML treatment were the prolongation of survival and, only for the patients eligible to alloSCT, the cure. Nowadays, the goals are more complex and more ambitious. ${ }^{6,19,20}$ If they are listed in a logical order, number one is the prevention of the progression towards accelerated phase (AP) and blastic phase (BP), to reduce to zero the risk of death for leukemia. Number two is to attain a length of survival comparable to that of non-leukemic people and a quality of life as close as possible to that of nonleukemic individuals. To achieve this latter objective, look not sufficient to clear the risk of dying of leukemia, but it is also necessary to avoid all deaths and complications related to the treatment, by limiting as much as possible the side-effects of the treatment while ensuring the compliance of the patients. At the same time, the patients should be assured to be no longer afraid of leukemia. In order to achieve all these goals, it is necessary to establish a specific professional network, because the disease is rare (1 to 1.5 new cases per year per 100.000 people) and a generalist can see only few such patients during his/her professional life. The management of CML should be modeled in a similar way to the management of diabetes mellitus type 1 , where patient care is based on the cooperation between a specialized centre and the home physicians.

The Time of Treatment. CML is a chronic disease. About $50 \%$ of patients are more than 60 years old, and about $50 \%$ of patients are asymptomatic. About $40 \%$ of patients are at a low risk of dying during the first two or three years, in absence of any affective treatment. ${ }^{2-4,6}$ Does that mean that the treatment can be delayed, until the disease becomes symptomatic? That's the current policy in several chronic diseases like chronic lymphocytic leukemia and multiple myeloma, where there is not yet full evidence that the balance between early treatment and result is positive. But this is not the case in CML. In CML, treatment, whatever it may be, must be positioned as early as possible, to stop the process leading to progression to AP and $\mathrm{BP}$. With minor and few exceptions, the battle can be victorious only if it is fought as early as possible.

Drugs and Stem Cell Transplantation. Most all the cytotoxic anticancer agents have some degree of efficacy in CML. Radiations was abandoned long time ago. BUS should no longer be used, with very few and temporary exceptions. HU, that has a rapid effect, a low cost, and a favorable safety profile, is still used to control the disease in the first few days waiting for the results of diagnostic tests, and occasionally and temporarily in patients who cannot take TKIs or are resistant to all TKIs. Anagrelide is not a drug for CML, but it is used sometimes to limit a very high platelet count. ${ }^{21}$ rIFN $\alpha$ was the standard of care, competing with allo SCT, for about 10 years, until the introduction of imatinib. ${ }^{1,2}$ Although the results of rIFN $\alpha$ were 
considerable, particularly in low risk patients, this agent has been almost completely replaced by TKIs in the first line treatment, and is not recommended second-line, in the patients who fail the TKIs. ${ }^{6,21}$ However, the combination of rIFN $\alpha$ with TKIs hold strong promises and is currently tested in prospective studies. ${ }^{22-24}$ AlloSCT was the first line treatment in the eligible patients for many years, now more than thirty, and is still the only treatment that can ensure a true cure, that is to say a complete and stable molecular negativity. ${ }^{7}$ Still, alloSCT is the best available treatment after progression to AP and BP. The argument of alloSCT in CML is not covered in this issue, and the reader is referred to several recent reports and reviews. ${ }^{1,5-7,25-27}$ To summarize, although nowadays the upper age of transplant is up to 70 years, and in most cases it is possible to find a suitable donor also outside the family, although the risk of transplantrelated mortality is substantially reduced, although the use of non-myeloablative regimens has helped to reduce transplant-related mortality and morbidity particularly in the elderly, the overall risk of mortality andcGVHD, in a population with a median age close to 60, are still hard to accept. Therefore, the current indication for allo SCT is TKIs-resistance in CP, and progression to $\mathrm{AP}$ and $\mathrm{BP} .{ }^{6,21}$ Unfortunately, the success of allo SCT is limited in AP and is very small in BP. ${ }^{7,28}$ Today, the masters of treatment are the TKIs that are described and discussed, in details, in this issue of the journal.

The Surrogate Markers of Outcome. The evaluation of the long term outcome (overall survival, OS, and progression-free survival, PFS) takes many years and does not help to adapt and to optimize the treatment in each single patient. Therefore, it is necessary to assess the hematologic, cytogenetic, and molecular responses as an early surrogate marker of the long term outcome (Table 1 and 2)., ${ }^{6,21}$ The first step is the hematologic response (HR) that must be complete within the first 3 months. Although the utility of evaluating HR is obscured by the large use of HU before TKIs, any patient who for any reason is not yet in CHR at 3 months, must be considered as a failure, mandating a change of treatment. ${ }^{6}$ The second step is the cytogenetic response (CyR), and the third step is the molecular response (MR). ${ }^{1,5}$ The progress in technology and standardization of the MR have now made it possible to use only the MR. ${ }^{6,29-32}$ The correspondence between the CyR and the MR is not absolute but is fairly good. Whenever is possible, both responses should be considered, for the best assessment of the response. ${ }^{6}$ According to ELN recommendations, the "failure", mandating a change of treatment, is defined: at 3 months as the lack of any CyR $(\mathrm{Ph}+>95 \%)$ and/or as a BCR-ABL1 transcripts level of more than 10\%; at 6 months as the absence of a Partial CyR (PCyR, $\mathrm{Ph}+>35 \%$ ) and/or as a BCR-ABL1

Table 1. Definition of response. The CCyR can be defined either by chromosome banding analysis (CBA) of at least 20 marrow cell metaphases, or by interphase fluorescence-in-situ-hybridization (I-FISH) of at least 200 marrow or blood nuclei (6). The other CyRs can be defined only by CBA of marrow cell metaphases. Molecular response must be assessed by standardized RT-Q-PCR of RNA extracted from buffy coat blood cells and must be expressed according to the International Scale (IS) $(6,28-31)$.

\begin{tabular}{|l|l|}
\hline Hematologic Response (HR): & $\begin{array}{l}\text { Complete: } \mathrm{WBC}<10 \mathrm{x} 10^{9} / \mathrm{L}, \text { Platelet count }<450 \times 10^{9} / \mathrm{L}, \text { no immature granulocytes in the differential, } \\
\text { and spleen non palpable. }\end{array}$ \\
\hline \multirow{3}{*}{ Cytogenetic Response (CyR): } & $\begin{array}{l}\text { Complete }(\mathrm{CCyR}): \text { no Ph+ metaphases or less than } 1 \% \text { BCR-ABL1 positive nuclei by I-FISH } \\
\text { Partial }(\mathrm{PCyR}): \text { Ph+ metaphases } 1-35 \%\end{array}$ \\
& $\begin{array}{l}\text { Minor/Minimal }(\mathrm{mCyR}): \text { Ph+ metaphases } 36-95 \% \\
\text { None: Ph+ metaphases }>95 \%\end{array}$ \\
\hline Molecular response (MR): & $\begin{array}{l}\mathrm{MR}^{4.5}: \text { BCR-ABL1 } \leq 0.003 \% \text { (IS) } \\
\mathrm{MR}^{4.0}: \text { BCR-ABL } 1 \leq 0.01 \% \text { (IS) } \\
\mathrm{MR}^{3.0} \text { (Major MR, MMR): BCR-ABL1 }<0.1 \% \text { (IS) }\end{array}$ \\
\hline
\end{tabular}

Table 2. Definition of response (failure or warning) to first line TKI treatments, according to ELN 2013 recommendations (6). "Failure" mandates for a change of treatment. "Warning" warns that the response must be monitored more frequently.

\begin{tabular}{|c|c|c|c|c|}
\hline & & HEMATOLOGIC RESPONSE & CYTOGENETIC RESPONSE & MOLECULAR RESPONSE \\
\hline \multirow{3}{*}{ FAILURE } & 3 months & Not full & None $(\mathrm{Ph}+>95 \%)$ & \\
\hline & 6 months & & $\begin{array}{l}\text { Less than partial } \\
\quad(\mathrm{Ph}+>35 \%)\end{array}$ & BCR-ABL > $10 \%$ \\
\hline & 12 months & & $\begin{array}{l}\text { Less than complete } \\
\qquad(\mathrm{Ph}+>0)\end{array}$ & $\mathrm{BCR}-\mathrm{ABL}>1 \%$ \\
\hline \multirow{3}{*}{ WARNING } & 3 months & & Minor/minimal $(\mathrm{Ph}+36-95 \%)$ & BCR-ABL > $10 \%$ \\
\hline & 6 months & & Partial $(\mathrm{Ph}+1-35 \%)$ & BCR-ABL 1-10\% \\
\hline & 12 months & & & BCR-ABL $0.1-1 \%$ \\
\hline
\end{tabular}


transcripts level > 10\%; at 12 months as the absence of a complete $\mathrm{CyR}(\mathrm{CCyR}, \mathrm{Ph}+=0)$ and/or as a BCRABL1 transcripts level of more than $1 \%$ (Table 2). ${ }^{6}$ In all these cases, a change of treatment is mandatory. However, there are cases when the response is neither a failure nor optimal and is defined as "warning", meaning that, in these cases, monitoring must be more frequent (Table 2). ${ }^{6}$ The optimal response to any firstline TKI treatment is shown in Table 3. In these cases, there are no indications for a change of treatment. ${ }^{6}$

Standard Treatment, Chronic Phase, Firstline. Three TKIs are currently registered for the first-line

\begin{tabular}{|ll|}
\hline 3 months & $\begin{array}{l}\text { BCR-ABL1 } \leq 10 \% \text { (IS) } \\
\text { and } / \text { or at least } \\
\text { PCyR }(\mathrm{Ph}+\leq 35 \%)\end{array}$ \\
\hline 6 months & $\begin{array}{l}\text { BCR-ABL1 }<1 \% \text { (IS) } \\
\text { and } / \text { or } \\
\text { CCyR }(\mathrm{Ph}+0)\end{array}$ \\
\hline $\mathbf{1 2}$ months & $\mathrm{MR}^{3.0}$ or MMR (BCR-ABL1 $\leq 0.1 \%$ (IS) \\
\hline
\end{tabular}

Table 3: Definition of an optimal response, according to ELN 2013 recommendations. ${ }^{6}$ Optimal response means that the treatment, whatever it is, must be continued. treatment of chronic phase (CML), namely imatinib (Gleevec or Glivec, Novartis Pharma), nilotinib (Tasigna, Novartis Pharma), and dasatinib (Sprycel, Brystol-Myers Squibb). The recommended doses are $400 \mathrm{mg}$ once daily, $300 \mathrm{mg}$ twice daily, and $100 \mathrm{mg}$ once daily, respectively. A higher dose of imatinib (300 to $400 \mathrm{mg}$ twice daily), a combination of imatinib $400 \mathrm{mg}$ once daily with rIFN $\alpha$, and a higher dose of nilotinib (400 $\mathrm{mg}$ twice daily), have been reported to be also very effective, but cannot be considered as standard treatment. ${ }^{11-13,22,23,33-36}$ Two prospective, company-sponsored studies comparing imatinib with nilotinib $^{11-13}$ and with dasatinib ${ }^{14,15}$ have reported a superiority of the two second generation TKIs, particularly in terms of MR rate, speed, and depth, with marginal benefit in PFS. These data are sufficient to include nilotinib and dasatinib in standard treatment recommendations, but are not enough to remove imatinib. ${ }^{6,21,37}$ There are not efficacy data that can help to make a decision between nilotinib and dasatinib. Therefore, the choice of standard treatment is based on the availability and the cost of the three drugs, on the professional experience of the prescriber, and on patient health status and comorbidities. A history, or a

- $\quad$ Loss of CHR

- $\quad$ Loss of CCyR

- Clonal chromosome abnormalities in $\mathrm{Ph}+$ cells

- Confirmed loss of $\mathrm{MR}^{3.0}$ (MMR), based on two consecutive tests, of which at least one must report a BCR-ABL1 transcripts level $\geq 1 \%$

- $\quad$ BCR-ABL1 kinase domain point mutations

Table 4: Definition of secondary failures, according to ELN 2013 recommendations. ${ }^{6}$ In all cases of secondary failure, a change of treatment is mandatory.

\begin{tabular}{|c|c|c|c|c|c|}
\hline BCR-ABL1 mutation & imatinib & nilotinib & dasatinib & bosutinib & ponatinib \\
\hline M244V & $\mathrm{R}$ & $S$ & S & $\mathrm{R}$ & S \\
\hline G250E & $\mathrm{R}$ & PR & S & $\mathrm{R}$ & S \\
\hline Y253K & $\mathrm{R}$ & $\mathrm{R}$ & S & NA & S \\
\hline E255K & $\mathrm{R}$ & $\mathrm{R}$ & S & $\mathrm{R}$ & PR \\
\hline T315I & $\mathrm{R}$ & $\mathrm{R}$ & $\mathrm{R}$ & $\mathrm{R}$ & S \\
\hline F317L & $\mathrm{R}$ & S & $\mathrm{R}$ & $\mathrm{R}$ & S \\
\hline M357T & $\mathrm{R}$ & S & S & S & S \\
\hline F359V & $\mathrm{R}$ & S & S & S & S \\
\hline L384M & $\mathrm{R}$ & S & S & S & NA \\
\hline H396R & $\mathrm{R}$ & $S$ & S & S & NA \\
\hline
\end{tabular}

Table 5: Sensitivity to the TKIs of the ten more frequent BCR-ABL1 mutations occurring in CP CML. R = resistant, PR = partially resistant, $\mathrm{S}=$ sensitive, NA = data not available. The definitions are extrapolated from the data reported in Ref. 6, Table 4. 
condition of high risk of arterial disease, diabetes, and pancreatic disease, can make the prescription of nilotinib problematic. ${ }^{6,38-42}$ A history, or a condition of high risk of hemorrhage, of respiratory diseases, autoimmune diseases, and infections complications, can make the prescription of dasatinib problematic. ${ }^{6,39,40,43-45}$ A history, or a condition of high risk of cardiac diseases, must be a warning for all three TKIs ${ }^{46,47}$ and requests to initiate the treatment at a dose lower than that recommended.

Standard Treatment, Chronic Phase, Second-Line. In the case of intolerance, it is recommended to switch to anyone of the other TKIs approved for first-line. The choice will depend on the side-effects of the first TKI, and on patient health status.

In the case of primary or secondary failure, if the first-line drug were imatinib, the choice will be between nilotinib and dasatinib; if the first-line drug were nilotinib or dasatinib, the other second generation TKI not already used, plus bosutinib and ponatinib should be considered. The change must be preceded by a mutational analysis, because the identification of a BCR-ABL1 mutation helps in the choice of the new treatment. ${ }^{6,48,49}$ The ten most frequent mutations, and their sensitivity to the TKIs are listed in Table 5. If the mutation is T315I, the choice will be always ponatinib, even if the first-line was imatinib., ${ }^{6,17,50,51}$

In the case of failure or intolerance to two TKIs, the choice will be anyone of the remaining TKIs. In such a situation, ponatinib is an important option. ${ }^{6,17,50,51}$

Standard Treatment, Accelerated or Blastic Phase Firstline. If the disease initiates in $\mathrm{AP}$ or $\mathrm{BP}$, and the patient is TKI-naïve, the standard treatment is imatinib (300 or $400 \mathrm{mg}$ twice daily) or dasatinib (140 mg once daily or $70 \mathrm{mg}$ twice daily) or nilotinib (400 $\mathrm{mg}$ twice daily). The response is assessed as for CP (Tables 1, 2 and 3 ).

If the disease progresses to $\mathrm{AP}$ or $\mathrm{BP}$ during TKI treatment, the choice is one of the TKIs that was not used in $\mathrm{CP}$, with a preference for ponatinib. The response is always assessed as for $\mathrm{CP}$ (Tables 1, 2, and 3 ).

Allogeneic Stem Cell Transplantation. AlloSCT is recommended: ${ }^{6}$

- For all the patients in BP at diagnosis or who progress to BP after TKI treatment, provided that a remission has been induced. AlloSTC in full BP is usually ineffective.

- For all the patients in AP at diagnosis not achieving an optimal response to the first line TKI or who progress to AP after TKI treatment (Table 3)
- For all CP patients who fail two TKIs and do not achieve an optimal response (Table 3) to the third line TKI

- For selected CP patients, who have high risk characteristics, fail the first TKI, and do not achieve optimal response (Table 3) to the second line TKI.

In all cases, a patient must be eligible for alloSCT. The definition of eligibility is never absolute because it is based on the balance between the risk of the disease and the risk of alloSCT.

Experimental Treatment. There are three categories of patients eligible for an experimental treatment.

The first category is that of the patients who fail TKIs and alloSCT, or cannot be transplanted. These patients need effective treatment, but such a treatment has not yet been found. ${ }^{27}$

The second category is that of the patients who fall in the "warning" definition of the response. They can do well if they continue the treatment, but they can do as well or better if treatment is changed. Examples are the trial protocols testing an early switch from imatinib to second generation TKIs, when the BCR-ABL1 transcripts level at 3 months is more than $10 \% .^{52-54}$

The third category is that of the patients who achieve an optimal response to first line treatment, but never achieve an MR as deep as it is necessary to try to discontinue therapy and achieve a treatment-free remission. ${ }^{55}$ Examples are the trial protocols testing $2^{\text {nd }}$ generation TKIs frontline, or a late switch from imatinib to second generation TKIs. ${ }^{56,57}$

The fourth category is that of the patients who achieve a stable optimal response and are eligible for a trial of treatment discontinuation or reduction ${ }^{58,59}$

A separate issue is that of the clinical value of the combination of TKI with IFNa. That combination is currently tested frontline in several prospective studies, to evaluate if it may have a favorable effect on response rate, PFS, and treatment-free remission. ${ }^{22-24,57}$

Discussion and Conclusions. Imatinib produced a big breakthrough in the course of CML. Today, after less than 15 years, we know more, we have more, and we want more. If, on one hand, we must realistically stay at standard treatment recommendations, on the other hand, we should continue to design new treatment protocols and to enroll new patients in prospective studies. This is not easy, because of the high efficacy of standard treatment. In any case, the treatment of CML must be guided by healthcare professionals with specific training and specific interest in CML, that are necessary for the optimization of the treatment and a proper utilization of the resources. The home physicians must be involved more and more in the care 
of the CML patient, because an optimal treatment ensures an average life expectancy, and the patient should no longer be considered as a patient at risk of dying of cancer, but as any other individual, at risk of developing complications and comorbidities of any type, that could also be triggered by the treatment itself. In some patients, particularly in the elderly where comorbidities are frequent and important and concomitant medications can create problems, treatment can be temporarily discontinued or reduced ${ }^{55,58}$ and in some patients the next ambitious step is to move towards a treatment-free remission. ${ }^{59}$

\section{References:}

1. Baccarani M, Saglio G, Goldman J, et al. Evolving concepts in the management of chronic myeloid leukemia: recommendations from an expert panel on behalf of the European LeukemiaNet. Blood 2006; 108:1809-1820. http://dx.doi.org/10.1182/blood-2006-02005686 PMid: 16709930

2. Hehlmann R, Hochhaus A, Baccarani M, on behalf of the European LeukemiaNet. Chronic myeloid leukemia. Lancet 2007; 370:34250. http://dx.doi.org/10.1016/S0140-6736(07)61165-9

3. Bjorkholm M, Ohm L, Eloranta S et al. Success story of targeted therapy in chronic myeloid leukemia: a population-based study of patients diagnosed in Sweden from 1973 to 2008. J Clin Oncol 2011;29:2514-2520. http://dx.doi.org/10.1200/JCO.2011.34.7146 PMid:21576640 PMCid:PMC3138632

4. Kantarjian H, O'Brien S, Jabbour E et al. Improved survival in chronic myeloid leukemia since the introduction of imatinib therapy: a single-institution historical experience. Blood 2012;119:1981-1987 http://dx.doi.org/10.1182/blood-2011-08358135 PMid:22228624 PMCid:PMC3311242

5. Baccarani M, Cortes J, Pane F, et al. Chronic myeloid leukemia: an update of concepts and management recommendations of European LeukemiaNet. J Clin Oncol 2009; 27:6041-6051 http://dx.doi.org/10.1200/JCO.2009.25.0779 PMid:19884523

6. Baccarani M, Deininger M, Rosti A. et al. European LeukemiaNet 2013 recommendations for the management of chronic myeloid leukemia. Blood 2013;122:885-892. http://dx.doi.org/10.1182/blood-2013-05-501569 PMid:23803709

7. Pavlu J, Szydlo RM, Goldman JM, and Apperley JF. Three decades of transplantation for chronic myeloid leukemia: what have we learned? Blood 2011;117(3):755-763. http://dx.doi.org/10.1182/blood-2010-08-301341 PMid:20966165

8. Talpaz M, Hehlmann R, Quintas-Cardama A, et al. Re-emergence of interferon-? in the treatment of chronic myeloid leukemia. Leukemia 2013; 27:803-12. http://dx.doi.org/10.1038/leu.2012.313 PMid:23238589 PMCid:PMC3703612

9. O'Brien SG, Guilhot F, Larson R, et al. Imatinib compared with interferon and low-dose cytarabine for newly diagnosed chronicphase chronic myeloid leukemia. N Engl J Med. 2003; 348:9941004 http://dx.doi.org/10.1056/NEJMoa022457 PMid:12637609

10. Hochhaus A, O'Brien SG, Guilhot F, et al. Six-year follow-up of patients receiving imatinib for the first-line treatment of chronic myeloid leukemia. Leukemia 2009;23:1054-1061. http://dx.doi.org/10.1038/leu.2009.38 PMid:19282833

11. Saglio G, Kim DW, Issaragrisil S, et al. Nilotinib versus imatinib for newly diagnosed chronic myeloid leukemia. N Engl J Med. 2010;362:2251-9. $\quad$ http://dx.doi.org/10.1056/NEJMoa0912614 PMid:20525993

12. Kantarjian HM, Hochhaus A, Saglio G, et al. Nilorinib versus imatinib for the treatment of patients with newly diagnosed chronic phase, Philadlephia chromosome-positive, chronic myeloid leukemia: 24-month minimum follow-up of the phase 3 randomised ENESTnd trial. Lancet Oncol 2011;12:841-851 http://dx.doi.org/10.1016/S1470-2045(11)70201-7

13. Larson RA, Hochhaus A, Hughes TP, et al. Nilotinib vs imatinib in patients with newly diagnosed Philadelphia chromosome-positive chronic myeloid leukemia in chronic phase: ENESTnd 3-year follow-up. Leukemia. 2012;26:2197-203.
Finally, the voice of the patient should deserve a major attention. The side effects of TKIs are reported as "tolerable" and "manageable", but when the sideeffects, even minimal, even mild, are chronic, the quality of life and the compliance to treatment will be affected. ${ }^{19,20,60-64}$ There are now new goals for the assessment of the quality of life and the symptoms burden, like the EORTC QLQ-CML24 and the MDASI-CML questionnaires. ${ }^{19,65-68}$ They should be regularly administered to allow the patients to contribute actively to treatment optimization. http://dx.doi.org/10.1038/leu.2012.134 PMid:22699418

14. Kantarjian H, Shah NP, Hochhaus A, et al. Dasatinib versus imatinib in newly diagnosed chronic-phase chronic myeloid leukemia. N Engl J Med. 2010;362:2260-70. http://dx.doi.org/10.1056/NEJMoa1002315 PMid:20525995

15. Kantarjian HM, Shah NP, Cortes JE et al. Dasatinib or imatinib in newly diagnosed chronic-phase chronic myeloid leukemia: 2-year follow-up from a randomized phase 3 trial (DASISION). Blood. 2012;119:1123. http://dx.doi.org/10.1182/blood-2011-08-376087 PMid:22160483

16. Cortes JE, Kim DW, Kantarjian HM, et al. Bosutinib versus imatinib in newly diagnosed chronic-phase chronic myeloid leukemia: results from the BELA trial. J Clin Oncol 2012;30:34863492. PMid:22949154

17. Cortes JE, Kim DW, Pinilla-Ibarz J, et al. A phase 2 trial of ponatinib in Philadelphia chromosome-positive leukemias. N Engl J Med 2013; 369(19):1783-96 http://dx.doi.org/10.1056/NEJMoa1306494 PMid:24180494

18. Experts in Chronic Myeloid Leukemia (Kantarjian H. et al). The price of drugs for chronic myeloid leukemia: a reflection on the unsustainable prices of cancer drugs: from the perspective of a large group of CML experts. Blood 2013; 121:4439-42 http://dx.doi.org/10.1182/blood-2013-03-490003 PMid:23620577

19. Baccarani M, Efficace F, Rosti G. Moving towards patientcentered decision-making in chronic myeloid leukemia: assessment of quality of life and symptom burden. Haematologica, 2013, in press.

20. Efficace F, Baccarani M, Breccia M, et al. Health-related quality of life in chronic myeloid leukemia patients receiving long-term therapy with imatinib compared to the general population. Blood 2011;118:4554-4560. http://dx.doi.org/10.1182/blood-2011-04347575 PMid:21750313

21. O'Brien S, Abboud $\mathrm{CN}$, Akhtari $\mathrm{M}$ et al, Clinical Practice Guidelines in Oncology. Chronic Myelogenous Leukemia, Version 1.2013, National Comprehensive Cancer Network (NCCN). J Natl Compr Canc Netw 2012;10:64-110.

22. Preudhomme C, Guilhot J, Nicolini FE, et al. Imatinib plus Peginterferon alfa-2a in chronic myeloid leukemia. N Engl J Med 2010;363:2511-2521. http://dx.doi.org/10.1056/NEJMoa1004095 PMid:21175313

23. Hehlmann R, Lauseker M, Jung-Munkwitz S, et al. Tolerabilityadapted imatinib $800 \mathrm{mg} / \mathrm{d}$ versus $400 \mathrm{mg} / \mathrm{d}$ versus $400 \mathrm{mg} / \mathrm{d}$ plus interferon-? in newly diagnosed chronic myeloid leukemia. J Clin Oncol 2011;29:1634-1642. http://dx.doi.org/10.1200/JCO.2010.32.0598 PMid:21422420

24. Simonsson B, Gedde-Dahl T, Markevarn B, et al. Combination of pegylated IFN-?2b with imatinib increases molecular response rates in patients with low- or intermediate-risk chronic myeloid leukemia. Blood 2011;118:3228-3235. http://dx.doi.org/10.1182/blood-2011-02-336685 PMid:21685374

25. Goldman M. How I treat chronic myeloid leukemia in the imatinib era. Blood 2007; 110:2828-2837 http://dx.doi.org/10.1182/blood2007-04-038943 PMid:17626839

26. Saussele S, Lauseker M, Gratwhol A, et al. Allogeneic 
hematopoietic stem cell transplantation for chronic myeloid leukemia in the imatinib era: evaluation of its impact within a subgroup of the randomized German CML Study IV. Blood 2010;115:1880-1885. http://dx.doi.org/10.1182/blood-2009-08237115 PMid:19965667

27. Warlick E, Ahn KW, Pedersen TL, et al. Reduced intensity conditioning is superior to nonmyeloablative conditioning for older chronic myelogenous leukemia patients undergoing hematopoietic cell transplant during the tyrosine kinase inhibitor era. Blood 2012;119(17):4083-4090. http://dx.doi.org/10.1182/blood-201202-409763 PMid:22408257 PMCid:PMC3350369

28. Hehlmann R. How I treat CML blast crisis. Blood 2012;120:737747 http://dx.doi.org/10.1182/blood-2012-03-380147 PMid:22653972

29. Hughes T, Deininger M, Hochhaus A, et al. Monitoring CML patients responding to treatment with tyrosine kinase inhibitors: review and recommendations for harmonizing current methodology for detecting BCR-ABL transcripts and kinase domain mutations and for expressing results. Blood 2006; 108:28-37 http://dx.doi.org/10.1182/blood-2006-01-0092 PMid:16522812 PMCid:PMC1895821

30. Branford S, Fletcher L, Cross NC, et al. Desirable performance characteristics for BCR-ABL measurement on an international reporting scale to allow consistent interpretation of individual patient response and comparison of response rates between clinical trials. Blood. 2008;112:3330-8. http://dx.doi.org/10.1182/blood2008-04-150680 PMid:18684859

31. Müller MC, Cross NC, Erben P, et al. Harmonization of molecular monitoring of CML therapy in Europe. Leukemia. 2009;23:195763. http://dx.doi.org/10.1038/leu.2009.168 PMid:19710700

32. Cross NCP, White HE, Müller MC, et al. Standardized definitions of molecular response in chronic myeloid leukemia. Leukemia 2012;26:2172:2175

33. Castagnetti F, Palandri F, Amabile M, et al. Results of high-dose imatinib mesylate in intermediate Sokal risk chronic myeloid leukemia patients in early chronic phase: a phase II trial of the GIMEMA CML WP. Blood 2009; 113:3428-34. http://dx.doi.org/10.1182/blood-2007-08-103499 PMid:19211938

34. Cortes JE, Baccarani M, Guilhot F, et al. Phase III, randomized, open-label study of daily imatinib mesylate $400 \mathrm{mg}$ versus $800 \mathrm{mg}$ in patients with newly diagnosed, previously untreated chronic myeloid leukemia in chronic phase using molecular end points: tyrosine kinase inhibitor optimization and selectivity study. J Clin Oncol 2010; 28:424-30. http://dx.doi.org/10.1200/JCO.2009.25.3724 PMid:20008622

35. Rosti G, Palandri F, Castagnetti F, et al. Nilotinib for the frontline treatment of $\mathrm{Ph}+$ chronic myeloid leukemia. Blood. 2009; 114:4933-8. http://dx.doi.org/10.1182/blood-2009-07-232595 PMid:19822896

36. Cortes JE, Jones D, O'Brien S, et al. Nilotinib as front-line treatment for patients with chronic myeloid leukemia in early chronic phase. J Clin Oncol 2010; 28:392-7. http://dx.doi.org/10.1200/JCO.2009.25.4896 PMid:20008621 PMCid:PMC2815701

37. Gurion R, Gafter-Gvili A, Vidal L, et al. Has the time for first-line treatment with second generation tyrosine kinase inhibitors in patients with chronic myelogenous leukemia already come? Systematic review and meta-analysis. Haematologica 2013;98:95$102 . \quad$ http://dx.doi.org/10.3324/haematol.2012.063172 PMid:22875617 PMCid:PMC3533665

38. Palandri F, Castagnetti F, Soverini S, et al. Pancreatic enzymes elevation in chronic myeloid leukemia patients treated with nilotinib after imatinib failure. Haematologica 2009;94:1758-1761. http://dx.doi.org/10.3324/haematol.2009.010496 PMid:19608673 PMCid:PMC2791949

39. Valent $P$. Severe adverse events associated with the use of secondline BCR/ABL tyrosine kinase inhibitors: preferential occurrence in patients with comorbidities. Haematologica 2011;96:1395-1397

40. Steegmann JL, Cervantes F, le Coutre P, et al. Off-target effects of BCR-ABL1 inhibitors and their potential long term implications in patients with chronic myeloid leukemia. Leuk Lymphoma 2012;53:2351-2362 http://dx.doi.org/10.3109/10428194.2012.695779 PMid:22616642

41. Giles FJ, Mauro MJ, Hong F, et al. Rates of peripheral arterial occlusive disease in patients with chronic myeloid leukemia in the chronic phase treated with imatinib, nilotinib, or non-tyrosine kinase therapy: a retrospective cohort analysis. Leukemia 2013;27:1310-1315. $\quad$ http://dx.doi.org/10.1038/leu.2013.69 PMid:23459450

42. Kim TD, Rea D, Schwarz M, et al. Peripheral artery occlusive disease (PAOD) in chronic phase chronic myeloid leukemia patients treated with nilotinib or imatinib. Leukemia 2013;27:13161321. http://dx.doi.org/10.1038/leu.2013.70 PMid:23459449

43. Quintas-Cardama A, Han X, Kantarjian H, Cortes J. Tyrosine kinase inhibitor-induced platelet dysfunction in patients with chronic myeloid leukemia. Blood 2009;114:261-263 http://dx.doi.org/10.1182/blood-2008-09-180604 PMid:19414863

44. Futosi K, Nemeth T, Pick R, et al. Dasatinib inhibits proinflammatory functions of mature human neutrophils. Blood 2012;119:4981-4991. http://dx.doi.org/10.1182/blood-2011-07369041 PMid:22411867 PMCid:PMC3367900

45. Zarbock A. The shady side of dasatinib. Blood 2012;119:4817$4818 . \quad$ http://dx.doi.org/10.1182/blood-2012-03-418582 PMid:22627592

46. Kerkela R, Grazette L, Yacobi R, et al. Cardiotoxicity of the cancer therapeutic agent imatinib mesylate. Nat Med 2006;12:908-916. http://dx.doi.org/10.1038/nm1446 PMid:16862153

47. Kim TD, le Coutre PD, Schwarz M, et al. Clinical cardiac safety profile of nilotinib. Haematologica 2012;97:883-889 http://dx.doi.org/10.3324/haematol.2011.058776 PMid:22271904 PMCid:PMC3366654

48. Soverini S, Gnani A, Colarossi S, et al. Philadelphia-positive patients who already harbour imatinib-resistant Bcr-Abl kinase domain mutations have a higher likelihood of developing additional mutations associated with resistance to second- or thirdline tyrosine kinase inhibitors. Blood 2009;114:2168-2171. http://dx.doi.org/10.1182/blood-2009-01-197186 PMid:19589924

49. Soverini S, Hochhaus A, Nicolini FE, et al. BCR-ABL kinase domain mutations analysis in chronic myeloid leukemia patients treated with tyrosine kinase inhibitors. Recommendations from an expert panel on behalf of European LeukemiaNet. Blood 2011;118(5):1208-1215. http://dx.doi.org/10.1182/blood-2010-12326405 PMid:21562040

50. O'Hare T, Shakespeare WX, Zhu X, et al. AP24534, a pan-BCR$\mathrm{ABL}$ inhibitor for chronic myeloid leukemia, potently inhibits the T315I mutant and overcomes mutation-based resistance. Cancer Cell 2009;16:401-412. http://dx.doi.org/10.1016/j.ccr.2009.09.028 PMid:19878872 PMCid:PMC2804470

51. Cortes JE, Kantarjian H, Shah NP, et al. Ponatinib in refractory chromosome-positive leukemias. N Engl J Med 2012;367:2075$2088 . \quad$ http://dx.doi.org/10.1056/NEJMoa1205127 PMid:23190221

52. Hanfstein B, Muller MC, Hehlmann R, et al. Early molecular and cytogenetic response is predictive of long-term progression-free and overall survival in chronic myeloid leukemia. Leukemia 2012;26:2096-2102. http://dx.doi.org/10.1038/leu.2012.85 PMid:22446502

53. Marin D, Hedgley C, Clark RE, et al. Predictive value of early molecular response in patients with chronic myeloid leukemia treated with first-line dasatinib. Blood 2012;120(2):291-294. http://dx.doi.org/10.1182/blood-2012-01-407486 PMid:22645182

54. Neelakantan P, Gerrard G, Lucas C, et al. Combining BCR-ABL1 transcript levels at 3 and 6 months in chronic myeloid leukemia: implications for early interventions strategies. Blood 2013;121:2739-2742. http://dx.doi.org/10.1182/blood-2012-11466037 PMid:23380743

55. Mahon FX, Rea D, Guilhot J, et al. Discontinuation of imatinib in patients with chronic myeloid leukaemia who have maintained complete molecular remission for at least 2 years: the prospective, multicentre Stop Imatinib (STIM) trial. Lancet Oncol 2010;11:1029-1035. $\quad$ http://dx.doi.org/10.1016/S14702045(10)70233-3

56. Shami PJ, Deininger M. Evolving treatment strategies for patients newly diagnosed with chronic myeloid leukemia: the role of second-generation BCR-ABL inhibitors as first-line therapy. Leukemia 2012;26:214-224.

http://dx.doi.org/10.1038/leu.2011.217 PMid:21844872

57. TIGER study. http://clinicaltrials.gov/show/NCT01657604

58. Russo D, Martinelli G, Malagola M, et al. Effects and outcome of a policy of intermittent imatinib treatment in elderly patients with chronic myeloid leukemia. Blood 2013;121:5138-44. 
http://dx.doi.org/10.1182/blood-2013-01-480194 PMid:23678005

59. EUROSKI study.

http://www.clinicaltrials.gov/ct2/show/NCT01596114

60. Rosti G, Castagnetti F, Gugliotta G, et al. Physician's guide to the clinical management of adverse events on nilotinib therapy for the treatment of CML. Cancer Treat Rev 2012;38:241-248. http://dx.doi.org/10.1016/j.ctrv.2011.07.004 PMid:21840128

61. Jabbour E, Deininger M, Hochhaus A. Management of adverse events associated with tyrosine kinase inhibitors in the treatment of chronic myeloid leukemia. Leukemia 2011;25:201-210. http://dx.doi.org/10.1038/leu.2010.215 PMid:20861918

62. Noens L, van Lierde MA, De Bock R, et al. Prevalence, determinants, and outcomes of nonadherence to imatinib therapy in patients with chronic myeloid leukemia: the ADAGIO study. Blood 2009;113:5401-5411. http://dx.doi.org/10.1182/blood-200812-196543 PMid:19349618

63. Marin D, Bazeos A, Mahon FX, et al. Adherence is the critical factor for achieving molecular responses in patients with chronic myeloid leukemia who achieve complete cytogenetic response on imatinib. J Clin Oncol 2010;28:2381-2388.

http://dx.doi.org/10.1200/JCO.2009.26.3087 PMid:20385986

64. Efficace F, Baccarani M, Breccia M, et al. Chronic fatigue is the most important factor limiting health-related quality of life of chronic myeloid leukemia patients treated with imatinib. Leukemia 2013;27:1511-1519. PMid:23417029

65. Efficace F, Baccarani M, Breccia M, et al. International development of an EORTC questionnaire for assessing healthrelated quality of life in chronic myeloid leukemia patients: the EORTC QLQ-CML24. Qual Life Res 2013. Epub 2013 Sep 13. http://dx.doi.org/10.1007/s11136-013-0523

66. http://groups.eortc.be/qol/

67. Williams LA, Garcia Gonzales AC, Ault P, Mendoza TR, et al Measuring the symptom burden associated with the treatment of chronic myeloid leukemia. Blood 2013;122:641-647. http://dx.doi.org/10.1182/blood-2013-01-477687 PMid:23777764

68. http://www3.mdanderson.org/depts/symptomresearch 